\title{
Effects of Peer Health Education on Sexual Health Knowledge and Attitudes of Tertiary Institution Students in Imo State, Nigeria
}

\author{
Sally Nkechinyere Onyeka Ibe ${ }^{*}$ (i), Jerome 0. Okafor ${ }^{2}$, Chikodi Ify Margaret Ezurike ${ }^{3}$, \\ Eunice Ogonna Osuala ${ }^{4}$, Casmir Ifeanyi Chikere Ebirim ${ }^{1}$, Chinyere Regina Nwufo ${ }^{1}$ \\ ${ }^{1}$ Department of Public Health, School of Health Technology, Federal University of Technology Owerri, Imo State, Nigeria \\ ${ }^{2}$ Department of Health Education and Human Kinetics, Faculty of Education, Nnamdi Azikiwe University Awka, Anambra State, \\ Nigeria \\ ${ }^{3}$ Department of Educational Foundation and Counselling, Faculty of Education, Imo State University Owerri, Imo State, Nigeria \\ ${ }^{4}$ Department of Nursing Science, Faculty of Allied Health Sciences, PAMO University of Medical Sciences, Port-Harcourt, Nigeria \\ Email: *sallyibe3@gmail.com
}

How to cite this paper: Ibe, S.N.O., Okafor, J.O., Ezurike, C.I.M., Osuala, E.O., Ebirim, C.I.C. and Nwufo, C.R. (2020) Effects of Peer Health Education on Sexual Health Knowledge and Attitudes of Tertiary Institution Students in Imo State, Nigeria. Health, 12, 638-652.

https://doi.org/10.4236/health.2020.126048

Received: May 9, 2019

Accepted: June 26, 2020

Published: June 29, 2020

Copyright $\odot 2020$ by author(s) and Scientific Research Publishing Inc. This work is licensed under the Creative Commons Attribution International License (CC BY 4.0).

http://creativecommons.org/licenses/by/4.0/

\begin{abstract}
This study was designed to determine effects of peer-health-education on sexual health knowledge and attitudes of tertiary institution students in Imo State Nigeria by determining the mean gain scores of sexual health knowledge and attitudes after peer health education. Quasi-experimental (pre-test-post-test) research design was employed. Two hundred students drawn from the University, Polytechnic and College of Education, using a multi-stage sampling technique participated in the peer sessions which were facilitated by trained peer educators. Data were analyzed using ANCOVA and Z-test. Findings revealed improved knowledge and attitudes on sexual health, as depicted by positive mean gain scores. Age group $16-20$ years had the highest mean gain score ( $\bar{X}=22.31$ ) of sexual health knowledge than the rest, while age group 26 - 30 years had the highest mean gain score $(\bar{X}=10.59)$ of sexual health attitudes. Males had higher mean gain score $(\bar{X}=26.05)$ of sexual health knowledge, while females had higher mean gain score $(\bar{X}=9.77)$ of sexual health attitudes. The first years (100 level students) had the highest mean gain score $(\bar{X}=25.71)$ of sexual health knowledge and also had the highest mean gain score $(\bar{X}=14.12)$ of sexual health attitudes. Level of study was significant both for knowledge and attitudes $(\mathrm{P}<0.01)$. It is recommended that peer-health-education be explored further as a method of communicating sexual health issues to tertiary institution students and youths generally.
\end{abstract}

\section{Keywords}

Sexual-Health, Peer-Education, Tertiary-Institution, Students, Knowledge, 
Attitudes

\section{Introduction}

There is increasing concern for sexual health promotion among youths globally, especially with challenges posed by sexually transmitted infections (STIs), including HIV infection. The need to educate people particularly the most-at-risk population on sexual health cannot be over emphasized for reducing the incidence of sexual health problems. Youths indulge in behaviours that expose them to the risk of sexual health problems [1] [2] [3] and this situation is yet to improve. Nigerian Government in her National Youth Policy defined the Nigerian youth as persons aged 18 years to thirty-five years [4]. Analysis of the National Policy on Education in Nigeria [5] showed that this period corresponded with the period the young person had left secondary school and spanned through the period of tertiary education. Some of these tertiary institution students were leaving the watchful eyes of their parents and family for the first time into unguarded freedom of campus life with increased pressure for sexual relationship and its attendant risks. It was noted that one third of the university freshmen have had sexual intercourse with at least two new partners since arriving the University, which placed them at the risk of unwanted pregnancy and STIs, among other sexual health risks [6].

The target population for this study was tertiary institution students who were presumed vulnerable to sexual health problems, partly due to inadequate sexual health knowledge and negative attitudes [7]. Youths, as depicted by tertiary institution students pursuing undergraduate programme in Nigeria, indulge in sexual risk behaviours such as; having multiple sexual partners, having sex for commercial gains, practice of unprotected sex, drug and alcohol abuse, sexual violence which can predispose to STIs, HIV infection, unplanned pregnancy and unsafe abortion with attendant complications. This situation underscored the need for, not only accurate sexual health information but also for an appropriate and acceptable strategy for delivering the message. It was expected that increase in health knowledge would influence attitudes positively as had been reported previously among university students [8] [9] [10] and even among secondary school students [11] [12].

It was observed that peer education had become increasingly popular since the advent of HIV and AIDS in reaching the at-risk populations with information [13]. Peer-education is the teaching or sharing of health information, values, and behaviours by members of similar age or status group [14] [15]. Peer education had been described as an approach [15] [16], a process, a strategy, a communication, and a tool [17], a method, philosophy and intervention strategy [15], for health promotion. Peer education is the teaching or sharing of health information, values, and behaviours by members of similar age or status group [14] [16]. 
Peer Education had occurred historically in different settings [18] and for a variety of age groups, backgrounds and interests [19]. Peer education operated on the principle that persons were more likely to be genuinely influenced by their peers than by outsiders [16]. Despite the noted increasing popularity of peer education, there were limited empirical works to the best knowledge of the authors of this work, on the use of peer education, particularly for sexual health among tertiary institution students in Nigeria.

This study was motivated by the need to test peer education strategy among tertiary institution students which would contribute to the search for appropriate strategy to communicate sexual health issues, a subject still shrouded in secrecy in this society. The study was concluded in 4014. The term "peer-education" was commonly used in literature, but "peer health-education" was preferred and used in this study to highlight sector interest. The independent variables of interest in this study were the identified demographic characteristics of the students which included age, gender and level of study (100 - 400 levels). Level of study reflects the current year the student occupies in relation to the duration of the course he or she is pursuing, for example, 100 level refers to first year or year-one in the program of study and so on. Inclusion was restricted to those students undergoing regular under-graduate studies in the Universities and College of Education, while for the Polytechnics those for Higher National Diploma (HND) Program. The results of this study created awareness on the positive effects of peer health education on sexual health knowledge and attitudes of the students and its immense benefits to programme planners who are constantly in search of a more effective and efficient strategy for communicating sexual health information to youths.

\section{Methods}

\section{Study design}

This study adopted the quasi-experimental (pre-test-post-test) design. The participants were assessed before the commencement of the peer health education sessions and again after the sessions. The sexual health education sessions were conducted by trained peer health educators who were preferentially selected by their peers for the peer health educators' training and the sessions lasted for six weeks.

\section{Area of the Study}

This study was conducted in Imo State of Nigeria, which is one of the 36 states in the country. Imo state has two Universities, two Polytechnics and one College of Education with regular undergraduate student enrolment of 63,297. These institutions were established to cater for the teeming youth population seeking tertiary education from within and outside the state. These institutions were located around the state capital, Owerri, which exposed the students to metropolitan social life styles which had profound negative implications on their sexual health. The institutions had limited hostel accommodations for their students 
resulting in most of the students residing in private accommodations outside the campuses with very high rent and the University authorities provided no oversight function in that regard. One of the universities, Imo State University, by design was non-residential, with the University playing no role in students' accommodation. It was a common practice for female students to share rooms with males living outside the campus to solve their accommodation problems. On the other hand, some of the students indulge in sex for commercial gains.

This behaviour of the students is exacerbated by their characteristic restless, inquisitive and risk taking common among youths which propelled them to indulge in at-risk sexual behaviours such as having multiple sexual partners, non-use/inconsistent use of condom and substance abuse which predispose them to sexual health problems.

\section{Population of the study}

The population of study comprised all the 63,297 (male 56.59\% \& female 43.41\%) registered regular undergraduate students of the two Universities, two Polytechnics (HND program only) and one College of Education (degree program only) in Imo state Nigeria. The institutions were Imo State University with targeted population of 26,522 (male $46.90 \%$, female 53.10\%); Federal University of Technology Owerri 18,829 (male 74.10\%, female 25.90\%); Alvan Ikoku Federal College of Education Owerri 7098 (male 51.75\%, female 48.25\%); Federal Polytechnic Owerri 6236 (male 56.63\%, female 43.37\%), and Imo Polytechnic Umuagwo 4612 (male $48.20 \%$, female 51.80\%). The tertiary institutions targeted were of interest because they were multidisciplinary in design and operation, offering wider reach and better representation of tertiary education than the monotechnics.

\section{Sample size and sampling techniques}

The sample size for the study comprised 220 students selected through a multistage sampling technique. Appropriate sampling technique such as cluster, simple random, systematic random methods were employed at the different stages. Twenty-two (22) students were selected from each level of study in the selected departments, after stratification by gender. Students from medical or health departments were excluded to rule out influence of programme of study. The 22 selected students in each level of study formed a study group. A total of 10 study groups were formed and each group preferentially selected two members (male - 1 and female - 1) from their groups, who were trained as peer educators. The rest 200 (20 members in a study group) participated as peers in the peer education sessions.

\section{Instrument for Data Collection}

The instrument for data collection was the "Peer health education sexual health knowledge and attitudes test (PESHKAT)" constructed by the researchers. The instrument had three sections which addressed demographic characteristics, sexual health knowledge and sexual health attitudes respectively. The instrument was validated for appropriateness by experts in the areas of interest, while the reliability was established using Kuder-Richardson-21 reliability coef- 
ficient for the knowledge section $(r=0.85)$ and Cronbach alpha reliability coefficient for the attitude section $(r=0.81)$.

Training of peer health educators and conduct of peer sessions

Training of the peer health educators was conducted with the aid of the Peer Education Training Manual containing six modules, prepared by the researchers but adapted from Imo State Ministry of Education Peer Education Training Manual for Young People and Peer Education Plus (PEP) Model for HIV intervention among most-at-risk populations developed by Society for Family Health and Action Aid International Nigeria. The modules were on adolescent sexuality, conception and pregnancy, sexually transmitted infections (STIs), and HIV, negotiating condom use for safer sex and sexual violence. The training was delivered in six sessions (one session per week), with each session lasting an average of two hours. The peer health educators facilitated the peer sessions on each module in line with their own training, module by module.

\section{Method of data collection}

The pre-test and post-test were conducted under examination conditions to allow for objective assessment of performance based on the test instrument (PESHKAT). A marking scheme was developed in line with the knowledge test questions which guided the scoring of the tests' questions.

\section{Method of data analysis}

The tests responses were scored and analysis done using Statistical Package for Social Sciences (SPSS). There were multiple choice questions for the knowledge section with only one correct answer for each question, while the attitude section was on a five-point scale graded along "strongly agree" to "strongly disagree" continuum. Mean score was calculated for the pre-test and for the post-test, then, the mean gain score was calculated. Z-test and analysis of covariance (ANCOVA) were employed for the statistical test and the level of significance was set at equal or less than 0.05 .

\section{Results}

Mean gain scores of sexual health knowledge of tertiary institution students of different age groups, gender and level of study, in Imo state Nigeria after peer education

Table 1 showed the results of the mean gain scores of sexual health knowledge of different age groups, gender and level of study after peer health education. Age group 16 - 20 years had a mean gain score of 22.31 and SD 19.39; age group 21 - 25 years had a mean gain score of 21.86 and SD of 21.97; age group 26 - 30 years had a mean gain score of 22.07 and SD of 25.21; while participants who were above 30 years had a mean gain score of 12.00 and SD of 8.00. Age group 16 - 20 years had higher sexual health knowledge mean gain score (22.31) than the rest of the age groups while those above 30 years had the lowest sexual health knowledge mean gain score of 12.00. Age group 26 - 30 years had wider SD (25.21) than the rest of the age groups while those above 30 years had the least 
Table 1. Mean gain scores of sexual health knowledge of tertiary institution students of different age groups, gender and level of study in Imo state after peer education $(n=200)$.

\begin{tabular}{cccccc}
\hline Variable & $\mathbf{n}$ & Pre-test & Post-test & Gain Score & SD \\
\hline & & $\bar{X}$ & $\bar{X}$ & $\bar{X}$ & \\
\hline Age last Birthday (in years) & & & & & \\
16-20 & 71 & 53.13 & 75.44 & 22.31 & 19.39 \\
$21-25$ & 99 & 50.87 & 72.73 & 21.86 & 21.97 \\
$26-30$ & 27 & 45.93 & 68.00 & 22.07 & 25.21 \\
Above 30 & 3 & 54.67 & 66.67 & 12.00 & 8.00 \\
Gender & & & & & \\
Male & & & & & \\
Female & 43 & 46.51 & 72.56 & 26.05 & 20.48 \\
Level of Study & 157 & 52.31 & 73.07 & 20.76 & 21.49 \\
100 level & & & & & \\
200 level & 40 & 53.71 & 79.43 & 25.71 & 18.32 \\
300 level & 40 & 49.30 & 73.10 & 23.80 & 18.39 \\
400 level & 60 & 52.76 & 70.21 & 17.45 & 22.19 \\
& 60 & 48.73 & 71.00 & 22.27 & 23.89 \\
\hline
\end{tabular}

SD (8.00). The males had a mean gain score of 26.05 and SD of 20.48; while the females had a mean gain score of 20.76 and SD of 21.49. Males had higher sexual health knowledge mean gain score than the females, while the females had wider SD than the males (Table 1).

The results of the mean gain scores of sexual health knowledge of different levels of study (year of study) after peer health education showed that one hundred level students had sexual health knowledge mean gain score of 25.71 and SD of 18.32. Two hundred level students had a mean gain score of 23.80 and SD of 18.39. Three hundred level students had a mean gain score of 17.45 and SD of 22.19. Four hundred level students had a mean gain score of 22.27 and SD of 23.89. One hundred level students had the highest mean gain score followed by two hundred level students then 400 level students and three hundred level students had the lowest. The 400 level students had a wider SD than students in other levels of study while those in 100 level of study had the least SD as shown in Table 1.

Mean gain scores of sexual health attitudes of tertiary institution students of different age groups, gender and level of study, in Imo state Nigeria after peer health education

Table 2 showed the results of the mean gain scores of sexual health attitudes of different age groups, gender and level of study after peer health education. Age group 16 - 20 years had a sexual health attitudes mean gain scores of 10.34 and SD 17.29; age group 21 - 25 years had a mean gain score of 8.42 and SD of 19.25; age group 26 - 30 years had a mean gain score of 10.59 and SD of 20.40; while those above 30 years had a mean gain score of -0.67 and SD of 9.29. Age group 26 - 30 years had higher sexual health attitudes mean gain score than the rest of the age groups, while those above 30 years had the lowest sexual health 
Table 2. Mean gain scores of sexual health attitudes of tertiary institution students of different age groups in Imo state after peer education $(n=200)$.

\begin{tabular}{cccccc}
\hline Variable & $\mathbf{n}$ & Pre-test & Post-test & Gain Score & SD \\
\hline & & $\bar{X}$ & $\bar{X}$ & $\bar{X}$ & \\
\hline Age last Birthday (in years) & & & & & \\
16-20 & 71 & 119.28 & 129.62 & 10.34 & 17.29 \\
$21-25$ & 99 & 117.59 & 126.01 & 8.42 & 19.25 \\
$26-30$ & 27 & 114.19 & 124.78 & 10.59 & 20.40 \\
Above 30 & 3 & 125.67 & 125.00 & -0.67 & 9.29 \\
Gender & & & & & \\
Male & & & & & \\
Female & 43 & 119.61 & 127.00 & 7.40 & 17.99 \\
Level of Study & 157 & 117.37 & 127.14 & 9.77 & 18.77 \\
100 level & & & & & \\
200 level & 40 & 118.62 & 132.74 & 14.12 & 15.50 \\
300 level & 40 & 118.90 & 122.53 & 3.63 & 16.53 \\
400 level & 60 & 118.35 & 125.26 & 6.91 & 20.06 \\
& 60 & 116.133 & 128.02 & 11.88 & 19.43 \\
\hline
\end{tabular}

attitudes mean gain score. Those in age group 26 - 30 years had wider SD than the rest of the groups while the participants above 30 years of age had the least as shown in Table 2. The males had a sexual health attitudes mean gain score of 7.40 and SD of 17.99 , while the females had a mean gain score of 9.77 and SD of 18.77. The females had higher sexual health attitudes mean gain score than the males and the females equally had a wider SD of 18.77 than the males (17.99).

One hundred level students had a sexual health attitudes mean gain score of 14.12 and SD of 15.50; two hundred level students had a mean gain score of 3.63 and SD of 16.53; three hundred level students had a mean gain score of 6.91 and SD of 20.06 while four hundred level students had a mean gain score of 11.88 and SD of 19.43. One hundred level students had the highest mean gain score of 14.12 , seconded by 400 level students (11.88) then 300 level students (6.91) and 200 level students had the lowest (3.63). Those in 300 level of study had wider SD than the rest (20.06) while those in 100 level of study had the least SD (15.50).

Result in Table 3 showed that there was no significant difference in the mean gain scores of sexual health knowledge of males and females after peer health education ( $\mathrm{Z}$-cal $=1.44, \mathrm{Z}$-tab $=1.97$ and $\mathrm{P}=0.15)$, though males had higher mean gain score of sexual health knowledge (26.05) than the females (20.76). Likewise, there was that there was no significant difference in the mean gain scores of sexual health attitudes of males and females after peer health education ( $\mathrm{Z}$-cal $=0.74, \mathrm{Z}$-tab $=1.97, \mathrm{P}=0.46$ ) but conversely sexual health attitudes mean gain score was higher for the females (9.77) than the males (7.40).

Analysis of covariance (ANCOVA) as presented in Table 4 showed that there was no significant difference in the mean gain scores of sexual health knowledge of the different age groups after peer health education $(\mathrm{F}=2.25, \mathrm{P}$-value $=0.08)$. 
Table 3. Summary of Z-test for mean gain scores of sexual health knowledge and sexual health attitudes of male and female tertiary institution students in Imo state after peer education $(n=200)$.

\begin{tabular}{|c|c|c|c|c|c|c|c|}
\hline Gender & $\mathrm{n}$ & Gain Score & SD & Known Variance & Z-cal & Z-tab & P-value \\
\hline & & $\bar{X}$ & & & & & \\
\hline \multicolumn{8}{|c|}{ Sexual health knowledge } \\
\hline \multirow[t]{2}{*}{ Male } & 43 & 26.05 & 20.48 & 419.33 & & & \\
\hline & & & & & 1.44 & 1.97 & 0.15 \\
\hline Female & 157 & 20.76 & 21.49 & 461.77 & & & \\
\hline \multicolumn{8}{|c|}{ Sexual health attitudes } \\
\hline \multirow[t]{2}{*}{ Male } & 43 & 7.40 & 17.99 & 323.53 & & & \\
\hline & & & & & 0.74 & 1.97 & 0.46 \\
\hline Female & 157 & 9.77 & 18.77 & 352.17 & & & \\
\hline
\end{tabular}

Table 4. Summary of ANCOVA testing for mean gain scores of sexual health knowledge of different age groups of tertiary institution students in Imo state after peer education ( $\mathrm{n}$ $=200)$.

\begin{tabular}{cccccc}
\hline Source & Type 111 Sum of Squares & df & Mean Square & F-ratio & P-value \\
\hline Corrected Model & $55,518.65(\mathrm{a})$ & 4 & $13,879.66$ & 77.17 & $<0.001$ \\
Intercept & $69,423.54$ & 1 & $69,423.53$ & 386.00 & $<0.001$ \\
Pre-Knowledge Score & $55,211.70$ & 1 & $55,211.70$ & 306.98 & $<0.001$ \\
AGE & 1211.82 & 3 & 403.94 & 2.25 & 0.08 \\
Error & $35,071.35$ & 195 & 179.85 & & \\
Total & $186,512.00$ & 200 & & & \\
Corrected Total & $90,590.00$ & 199 & & &
\end{tabular}

${ }^{\mathrm{a}} \mathrm{R}$ Squared $=0.61$ (Adjusted R Squared $\left.=0.61\right)$.

There was significant difference in mean gain scores of sexual health knowledge of students of different levels of study after peer health education as presented on Table $5(\mathrm{~F}=4.64$, P-value $<0.001)$. Results on Table 6 revealed no statistical significance difference in the mean gain scores of sexual health attitudes of students of different age groups after peer health education $(\mathrm{df}=3, \mathrm{~F}$-ratio $=1.15, \mathrm{P}$ $=0.33$ ), but there was significant difference in the mean gain scores of sexual health attitudes of students of different levels of study after peer health education $(\mathrm{F}=4.53, \mathrm{P}<0.001)$ as shown in Table 7.

\section{Discussion}

Effects of peer health education on sexual health knowledge of tertiary institution students in Imo State Nigeria

Peer health education produced positive effect on sexual health knowledge of the students. Students as youths pay attention to their peers who usually constitute their main source of sexuality information. This finding corroborates with 
Table 5. Summary of ANCOVA testing for mean gain scores of sexual health knowledge of tertiary institutions students of different levels of study in Imo state after peer education $(n=200)$.

\begin{tabular}{cccccc}
\hline Source & Type 111 Sum of Squares & df & Mean Square & F-ratio & P-value \\
\hline Corrected Model & $56,722.87(\mathrm{a})$ & 4 & $14,180.72$ & 81.65 & $<0.001$ \\
Intercept & $102,108.19$ & 1 & $102,108.19$ & 587.92 & $<0.001$ \\
Pre-Knowledge Score & $54,809.92$ & 1 & $54,809.92$ & 315.58 & $<0.001$ \\
LEVEL & 2416.05 & 3 & 805.35 & 4.64 & $<0.001$ \\
Error & $33,867.13$ & 195 & 173.68 & & \\
Total & $186,512.00$ & 200 & & & \\
Corrected Total & $90,590.00$ & 199 & & & \\
\hline
\end{tabular}

${ }^{\mathrm{a}} \mathrm{R}$ Squared $=0.63$ (Adjusted R Squared $\left.=0.62\right)$.

Table 6. Summary of ANCOVA testing for mean gain scores of sexual health attitudes of tertiary institution students of different age groups in Imo state after peer education $(\mathrm{n}=$ 200).

\begin{tabular}{cccccc}
\hline Source & Type 111 Sum of Squares & df & Mean Square & F-ratio & P-value \\
\hline Corrected Model & $31,747.18(a)$ & 4 & 7936.80 & 41.86 & $<0.001$ \\
Intercept & $33,336.97$ & 1 & $33,336.97$ & 175.84 & $<0.001$ \\
Pre-Attitude Score & $31,251.96$ & 1 & $31,251.96$ & 164.84 & $<0.001$ \\
AGE & 653.94 & 3 & 217.98 & 1.15 & 0.33 \\
Error & $36,969.30$ & 195 & 189.59 & & \\
Total & $85,866.00$ & 200 & & &
\end{tabular}

${ }^{\mathrm{a}} \mathrm{R}$ Squared $=0.46$ (Adjusted R Squared $\left.=0.45\right)$.

Table 7. Summary of ANCOVA testing for mean gain scores of sexual health attitudes of tertiary institution students of different levels of study in Imo state after peer education (n $=200)$.

\begin{tabular}{cccccc}
\hline Source & Type 111 Sum of Squares & df & Mean Square & F-ratio & P-value \\
\hline Corrected Model & $33,543.74(\mathrm{a})$ & 4 & 8385.94 & 46.49 & $<0.001$ \\
Intercept & $35,504.96$ & 1 & $35,504.96$ & 196.84 & $<0.001$ \\
Pre-Attitude Score & $30,549.79$ & 1 & $30,549.79$ & 169.37 & $<0.001$ \\
LEVEL & 2450.49 & 3 & 816.83 & 4.53 & $<0.001$ \\
Error & $35,172.74$ & 195 & 180.37 & & \\
Total & $85,866.00$ & 200 & & & \\
Corrected Total & $68,716.48$ & 199 & & & \\
\hline
\end{tabular}

${ }^{\mathrm{a}} \mathrm{R}$ Squared $=0.488$ (Adjusted R Squared $\left.=0.478\right)$.

the findings of earlier and similar studies [9] [10] [20]. The youngest age group (16 - 20 years) had the highest sexual health knowledge mean gain score. Ado- 
lescence is an impressionistic stage in human development with high affinity for peers. Peer facilitating of sessions would likely arouse interest and elicit greater attention than the older students. Males had higher mean gain scores of sexual health knowledge than females though not significant. Females were usually shy and uncomfortable discussing such culturally sensitive topic as sexual health in the presence of males. Naturally men are more open in discussing sexual issues than females which might contribute to their having higher knowledge mean gain score than females. These findings agreed with that of earlier related study [7], though that study assessed just knowledge and not knowledge mean gain score which is usually determined after an intervention to ascertain the effect of such intervention. On the contrary, a higher knowledge that was significant for female University students in Iran than the males after peer coordinated education [8]. Also, higher knowledge score was reported among female University students than the males though there was no significant difference [21], but that study employed a survey design with sample drawn from students in health related program unlike this. These findings pointed to the need to target gender differences when designing peer health education programs that address sexually related subjects. Male and female groups should be separated for peer sexual health education and the groups should be assigned same sex peer health educator. Such an arrangement would make for a more conducive milieu for effective participation and equal learning opportunity for the different gender groups.

One hundred (100) level students had the highest mean gain score of sexual health knowledge with no significant difference among the different levels of study. This performance of 100 level students was expected, as entering the University was a motivating factor to acquire more knowledge leading to greater enthusiasm. 100 level students were just about two months old in the institutions when this study was conducted which could lead to high expectations and readiness to explore new areas of learning. The comparatively lower performance of 300 level students was surprising. One would have expected better performance when compared with other levels of study having spent three years in the tertiary institution. This highlighted the importance of timing such peer health education activity in relation to level of study. Targeting students in 100 level and timing such peer health education program immediately the freshmen conclude their registration will yield better results.

Effects of peer health education on sexual health attitudes of tertiary institution students in Imo State Nigeria

Sexual health attitudes of the tertiary institution students improved after peer health education which was a positive effect. There was a positive link between increase in sexual health knowledge and the resultant improved sexual health attitudes. Peer health educators highlighted the severity of sexual health problems to their peers during the peer sessions which resulted in positive attitudes. These findings corroborated with findings of other studies, such as that which recorded improved attitudes after peer education training on AIDS prevention knowledge, attitudes and life skills, among sixteen colleges and universities in Beijing 
China [20]. Also, more liberal attitudes was reported after peer-led sex education in twenty-five English schools [12], and improvement in attitudes of students in relation to HIV and AIDS was similarly reported in a study that assessed the effectiveness of peer health education on HIV and AIDS [10].

Participants that were above 30 years recorded negative mean gain score of sexual health attitudes (though very minimal), despite positive sexual health knowledge mean gain score. This did not collaborate with the assumption that increased knowledge would result in improved attitudes, as seen in the other age groups in this study. The sexual health attitudes mean gain scores of peers did not actually present any particular sequence among the different age groups. The explanation could hinge on the assertion that attitudes are formed over time and from multifarious influences existing in one's environment including beliefs, values and traditions among others. These factors are strongly rooted, cutting across age groups which might make it difficult to establish a sequential trend in the attitude performance of the various age groups. This finding on sexual health attitudes aligns with findings of another study [22], in which age was not significantly related to sexual attitudes of University students in Malaysia.

Female students had higher sexual health attitudes mean gain score than the males, with no statistical significant difference. This finding might be because females by their nature and nurture were more poised for attitudinal change in health related issues and showed emotions more than males. Females were usually more responsive in the affective domain than their male counterparts. Also, the culture, gender and sexual attitudes relationship could be contributory to the nature of the result. Socialization process, division of labour and gender roles relating to sexuality, reproduction and care-giving created major but different impressions in the psyche of males and females, a situation which could be traced to early childhood. Females were prone to develop positive sexual health attitudes more easily than males in the African societies. In many societies in Africa, males receive accolades for their negative sexual behaviours, such as multiple sexual partnering, sexual violence and the likes while the opposite treatment was meted to their female counterparts for the same act. Such situation would likely inculcate negative psyche on males. These findings corroborate results documented in another report [7] which showed that female University students in Malaysia had better sexual health attitudes than their male counterparts, as well others [8] [23], though in one of the studies comparison was done based on the aggregate scores and the study design was a descriptive survey [23], which differed from the quasi-experimental design employed for this study. Gender differences should be specifically addressed in peer health education. Males need a more elaborate peer health education programme that is gender specific and tailored to their needs for improved sexual health attitudes. Moreover, males-alone programme would be more advantageous than males and females combined programme. This should be of great relevance to policy makers and programme planners working in the area of peer health education, sexual health and related areas. 
There were positive mean gain scores of sexual health attitudes of peers at all levels of study. One hundred level (year one) students had the highest which was statistically significant $(\mathrm{P}<0.001)$. The 100 level students were fresh students with the mind to acquire higher and better knowledge to shape their perception. The tendency for year one (100 level) students to be more influenced by peer health educators through modelling as described in Bandura's Social Learning Theory was higher. Students in other levels of study also had positive sexual health attitudes mean gain scores which increased sequentially but in a descending order with level of study. Other students aside those in 100 level might experience some degree of psychological satisfaction associated with success so far achieved in climbing the ladder rungs of higher academic pursuit, which could affected their perception of the intervention. Their psychological state could be associated with the feeling of 'I know it' which might affect level of performance. However, it was expected that having spent more years in tertiary institution with more exposures to life's realities and gaining more experience, they would be more serious with issues such as presented in sexual health peer health education sessions. Drawing from the Health Belief Model developed by Hochbaun and colleagues, as adapted in this study, peer health education served as cue to action to activate the peers' readiness to learn. The peer educators served as significant others who exposed the threat of sexual health problems to their peers through their facilitation, resulting in improved sexual health attitudes. Policy makers and programme planners in peer health education and sexual health programmes should hence take advantage of these findings for result oriented programmes.

\section{Limitation}

There was disparity in the number of males and females enrollment in the levels of study, giving rise to unequal number of males and females in the sample. Having equal males and females in the sample could have made for better comparison of the performance of the different sexes. However, this did not affect the result as proportional sample was taken from each level after stratification by gender to fill that gap.

\section{Conclusions}

Peer health education proved useful in communicating sexual health issues as substantiated by the positive effects reported in this study. Peer health education can therefore be employed as a veritable method for addressing the low sexual health knowledge and attitudes of youths generally and tertiary institution students in particular.

Age, gender and level of study of tertiary institution students have implication on the effects of peer health education on sexual health knowledge and attitudes. The younger undergraduates (adolescents) and freshmen should be the priority targets for sexual health peer health education interventions because of greater 
positive effects recorded among them and which aligns to the principle of "catch them young".

Gender disaggregated groups yield more positive result than groups with both sexes combined for sexual health peer health education sessions and this should be taken into consideration by relevant authorities who design and implement such programmes (government, educational institutions and non-governmental organizations working with youths in the area of sexual health).

\section{Recommendations}

The recommendations below were based on the findings of this study.

1) Tertiary institutions should introduce peer health education for communicating sexual health issues in Nigeria which can be a compulsory activity for freshmen. It will expose the students especially the younger ones to accurate sexual health information thereby preventing at-risk sexual behaviours which they usually engage in.

2) Sexual health related peer education sessions should be gender disaggregated with same sex peer educator facilitating the sessions. This will loosen some of the inhibitions that negatively affect females in particular when it comes to discussions on sex and sexuality.

3) Peer health education technique should be explored further to determine effect on sexual behaviours of tertiary institution students which was not covered in this study.

\section{Acknowledgements}

The researchers are grateful to the management and students of the institutions that participated in the study.

\section{Conflicts of Interest}

The authors declare no conflicts of interest regarding the publication of this paper.

\section{References}

[1] Hazlina, M.R. and Mohd-Sukur, S. (2002) Knowledge and Perception of HIV/AIDS among the Public and Teacher Trainees. In: Riji, H.M., Joseph, K. and Pataki-Schweizer, Eds., HIVIAIDS the Realities, the Challenges, Ministry of Health, Kuala Lumpur, 130-136.

[2] Centre for Disease Control and Prevention (2003) Healthy People 2010: Responsible Sexual Behaviour.

http://www.healthypeople.gov/Document/html/uih/uih bw/uih 4.htm

[3] Centre for Disease Control and Prevention (2004) Trends in Reportable Sexually Transmitted Diseases in the United States. http://www.cdc.gov/std/stats/trends2004.htm

[4] Federal Republic of Nigeria (2001) National Youth Policy. Author, Abuja.

[5] Federal Republic of Nigeria (FRN) (2004) Nigerian Policy on Education. Author, 
Abuja.

[6] Caron, S.L. and Halteman, W.A. (1993) Predictors of Condom Related Behaviour among First Year College Students. Journal of Sex Research, 30, 252-250.

https://doi.org/10.1080/00224499309551709

[7] Jahanfar, S., Sann, L.M. and Rampai, L. (2010) Sexual Behaviour, Knowledge and Attitude of Non-Medical University Students towards HIV/AIDS in Malaysia. Shiraz E Medical Journal, 11, 126-129. https://www.sid.ir/en/journal/ViewPaper.aspx

[8] Jodati, A.R., Nourabadi, G.R., Hassanzadeh, S., Dastgiri, S. and Sedaghat, K. (2007) Impact of Education in Promoting the Knowledge of and Attitude to HIV/AIDS Prevention: A Trial of 17,000 Iranian Students. International Journal of Sexually Trasmitted Disease \& AIDS, 18, 407-409. https://doi.org/10.1258/095646207781024829

[9] Rabieipoor, S., Taskin, L. and Mikaili, P. (2011) Empowering of Oromieh University Female Students in Relation to Their Sexual and Reproductive Health by Peer Education Method. Annals of Biological Research, 2, 149-156.

[10] Zhou, L., Guo, J., Ma, Z., Fan, L., Gu,Y., Guan, Z. and Zhou, B. (2011) Effectiveness of Peer Education on Knowledge and Attitudes of HIV/AIDS in Shenyeng China. World Medical and Health Policy, 3, Article 5. https://doi.org/10.2202/1948-4682.1147

[11] Osowole, O.S. and Oladipo, O. (2000) Effect of Peer Education on Deaf Secondary School Students' HIV/AIDS. Journal of Reproductive Health, 4, 93-103. https://doi.org/10.2307/3583453

[12] Strange, V., Forrest, S., Oakley, A. and The RIPPLE Study Team (2002) Peer-Led Sex Education: Characteristics of Peer Educators and Their Perceptions of Impact on Them of Participation in a Peer Education Programme. Health Education Resources, 17, 327-337. https://doi.org/10.1093/her/17.3.327

[13] Ward, J., Hunter, G. and Power, R. (1997) Peer Education as a Means of Drug Prevention and Education among Young People: an Evaluation. Health Education Journal, 56, 251-263. https://doi.org/10.1177/001789699705600305

[14] Sciacca, J.P. (1987) Students Peer Education: A Powerful Jet Inexpensive Helping Strategy. The Peer Facilitator Quarterly, 5, 4-6.

[15] Population Council (1996) Focus on the Philippine DMPA Reintroduction Programme: Continuing Users vs Drop-Outs. Population Council Research News (Asia and near East Operation Research and Technical Assistance Project No. 7), 1-2.

[16] Foghlam, A. (2013) Peer Education Approaches to Learning, Teaching and Assessment. Education Scotland, 1-3.

http://www.educationsscotland.gov.uk/learningteachingandassessment/approaches/ peered

[17] Adamchak, S.E. (2006) Youth Peer Education in Reproductive Health and HIV/AIDS: Progress, Process and Programming for the Future. Youth Issues Paper 7. Youthnet. Family Health International, Arlington, VA-USA.

[18] Bleeker, A. (2001) Drug Use and Young People: Rational for Drug Stop Project (D.S.P.). Presentation for 2nd International Drug and Young People Conference, Melbourne, 4-6 April 2001, 1-15.

[19] Truong, J. (2008) Peer Education: A Viable Approach for Reaching Youth. Global Health Technical Briefs. Maximizing Access and Quality (MAQ) Initiative.

[20] Chan, J., Zhang, L., Liu, Y. and Wang, J. (2000) The Impact of Sex-Education Training on AIDS Prevention. Knowledge, Attitudes and Life Skills of Students. In- 
ternational Conference on AIDS, 1-4 July 2000, Abstract No. ThPeC5375. http://gateway.nlm.nih.gov/meetingAbstracts/ma?F=102241918.htlm

[21] Elit, L., Trim, K., Mohan, R., Nastos, S. and Harnish, D. (2009) The Knowledge and Attitude of University Students Concerning HPV Vaccine and Cervical Screening. Clinical Medicine: Reproductive Health, 3, 1-8. http://www.la-press.com https://doi.org/10.4137/CMRH.S2973

[22] Low, W.Y. (2004) Impact of Sexual Health Course on Malaysian University Students. Medical Journal of Malaysia, 59, 443-449.

[23] Castora, M. (2005) An Assessment of University Students' Knowledge, Attitudes and Behaviour towards Sex. The University of Central Florida Undergraduate Research Journal, 1, 28-37. 